\title{
Climate Change Impacts on Runoff Regimes at a River Basin Scale in Central Vietnam
}

\author{
Do Hoai Nam*, Keiko Udo, and Akira Mano \\ Disaster Control Research Center, Tohoku University, Sendai, Japan
}

Received 30 September 2011, accepted 3 May 2012

\begin{abstract}
Global warming has resulted in significant variability of global climate especially with regard to variation in temperature and precipitation. As a result, it is expected that river flow regimes will be accordingly varied. This study presents a preliminary projection of medium-term and long-term runoff variation caused by climate change at a river basin scale. The large scale precipitation projection at the middle and the end of the $21^{\text {st }}$ century under the A1B scenario simulated by the CGCM model (MRI \& JMA, $300 \mathrm{~km}$ resolution) is statistically downscaled to a basin scale and then used as input for the super-tank model for runoff analysis at the upper Thu Bon River basin in Central Vietnam. Results show that by the middle and the end of this century annual rainfall will increase slightly; together with a rising temperature, potential evapotranspiration is also projected to increase as well. The total annual runoff, as a result, is found to be not distinctly varied relative to the baseline period 1981 - 2000; however, the runoff will decrease in the dry season and increase in the rainy season. The results also indicate the delay tendency of the high river flow period, shifting from Sep-Dec at present to Oct-Jan in the future. The present study demonstrates potential impacts of climate change on streamflow regimes in attempts to propose appropriate adaptation measures and responses at the river basin scales.
\end{abstract}

Key words: Climate change, Precipitation, Runoff variation

Citation: Nam, D. H., K. Udo, and A. Mano, 2012: Climate change impacts on runoff regimes at a river basin scale in Central Vietnam. Terr. Atmos. Ocean. Sci., 23, 541-551, doi: 10.3319/TAO.2012.05.03.03(WMH)

\section{INTRODUCTION}

Climate change is considered to be one of the major challenges for human beings in the $21^{\text {st }}$ century. It has been causing enormous adverse impacts on mankind, environment and ecosystem on a global scale. It is obvious that many sectors are being affected by climate change. For instance, a reduction of agriculture production and increased risk of animal and plant extinction are caused by rising temperature; destruction of infrastructure and loss of lives are triggered by severe flood events; on the other hand, severe droughts occurring in dry seasons probably enhance water conflict. A regional assessment of climate change on mankind, to some extent, was addressed in the Fourth Assessment Report by the IPCC ${ }^{1}$ (2007).

The main indicators of climate change are increased temperature and variability of precipitation. Observations showed that the last decade has been recorded as warmest years in the last hundred years. The surface temperature increase was observed for the entire globe, about $0.74^{\circ} \mathrm{C}$ over the last 100 years (IPCC 2007). It is projected that by the end of this century (period 2090 - 2099), the global average surface temperature will be likely increasing by $2.8^{\circ} \mathrm{C}$ relative to period 1980 - 1999 which is based on scenario A1B simulation. Increases in temperature, therefore, are expected to result in changes in hydrological cycles, especially the increases of spatiotemporal variability of precipitation. It is very likely that river flow regimes will be varied. High river flow is projected to increase in most tropical regions due to the higher frequency of extreme precipitation. On the other hand, more serious drought events during dry periods might increase a threat of water shortage and further inland salinity intrusion.

\footnotetext{
* Corresponding author

E-mail:nam@potential1.civil.tohoku.ac.jp
}

1 Intergovernmental Panel on Climate Change. 
Assessment of hydrological responses to climate change has been addressed since the middle of the last century. It has been continuously revised as a result of the improvement of climate model output in terms of spatiotemporal resolution and prediction capability. Most assessments have been based primarily on a coupling approach between global atmospheric general circulation models (GCMs), which are designed to simulate past and current climate then used to predict the future state of global climate based on specific scenarios of green-house gas emission, and hydrological models. GCMs are generally operational with very coarse spatial resolution, of the order of hundreds kilometres, given the limitation of computational capacity. Small scale effects of land surface, as a result, are not resolved by GCMs. Application of direct model output often results in large discrepancies of runoff simulations. It was reported that direct application seems to be suitable for assessments in macro river basins, as stated in the literature (Xu 1999). Given the limitation of the GCMs, downscaling the model output is often employed to derive sub-grid precipitation used for hydrological simulation. Downscale technology is simply classified into dynamic downscaling and statistical downscaling methods. The dynamic downscaling method, otherwise known as regional climate models, can provide higher spatiotemporal resolution of model output, but is costly to run. On the other hand, a statistical downscaling method has exhibited a cost-effective method which has been widely applied in most climate change impact assessments. An inclusive review of downscaling methods for GCMs was presented by Wilby and Wigley (1997).

Changes in river flow regimes in some largest river basins were addressed in the latest assessment, the Fourth Assessment Report conducted by the IPCC (2007), which employs advanced climate models developed by leading modelling institutions around the world (the Coupled Model Inter-comparison Project - Phase 3). The report indicated that river flows tend to decrease significantly during dry periods. Together with rising temperature and rapid population growth most of these river basins are facing severe water scarcity by the middle of this century. Other studies indicated that the increased frequency of flood runoff during rainy seasons is projected by most climate change scenarios (Gellens and Roulin 1998). However, it is expected that the hydrological responses are completely distinct for specific river basins given the differences in topography and weather patterns.

Located in South-east Asia, Vietnam is one of the most affected countries by climate change which has been aware of a major challenge in this century. With respect to adaptation strategies to climate change, estimates of river flow variability within a river basin scale can provide valuable input for decision makers and exposed communities for the better development of an adaptation strategy. This study presents a projection of medium-term and long-term runoff variation in the upper Thu Bon River basin as a case study. The large scale precipitation projection at the middle and the end of the $21^{\text {st }}$ century under the A1B scenario simulated by a GCM is statistically downscaled to the basin scale and then used as input for a distributed hydrological model for runoff variation assessment.

\section{STUDY AREA AND METHODOLOGY}

\subsection{Study Area}

The catchment selected in this study is the upper reach of the Thu Bon River, which belongs to the Vu Gia-Thu Bon River system as illustrated in Fig. 1, with an area of $3150 \mathrm{~km}^{2}$. Due to rapid economic development, the change in land use for agricultural expansion and increasing population have been observed throughout the basin except the most upstream parts covered by forest. The study area, thus, has been coping with water-related issues given by climate change impacts. It often experiences large scale flooding disasters during wet seasons, from September to December, every year. These floods are usually caused by intense widespread rainfall. On the other hand, low river flow in the remaining months associated with sea level rise often leads to severe drought and further inland salinity intrusion. With regard to distribution of soil type, it is simply grouped in the following 3 categories: (i) alluvium distribution mainly found in downstream parts of the river basin and in some medium high places; (ii) red and yellow podzol in most medium high and elevated places; and (iii) lithosol distributed mainly in elevated areas, known as most upstream parts. Hydraulic conductivity of soil type for loam, clay-loam, and clay varies from $10^{-4}$ to $10^{-7} \mathrm{~m} \mathrm{~s}^{-1}$.

\subsection{General Circulation Model}

Regarding the contribution to phase 3 of the Coupled Model Inter-comparison Project, a large number of GCMs were developed by leading climate modeling centers in the world such as in Europe, America, and Asia. These models generally provide experimental simulations of global climate with relatively coarse spatiotemporal resolution; model output is usually on monthly basis for a grid cell distance of 2 - 5 degrees. Each modeling center, however, has its own simulation purposes, and is very much dependent on computational capability. The models, therefore, might be different in terms of physical parameterization, time slice and spatiotemporal resolution. This study used the output of the coupled general circulation model developed by the Meteorological Research Institute (MRI) in cooperation with Meteorological Agency of Japan (JMA), simply referred as CGCM, with spatial resolution of 2.8 degrees (approximate $300 \mathrm{~km}$ ). The CGCM is currently considered to be one of the most advanced global climate models which reproduces the past, present and future climate patterns with a high con- 


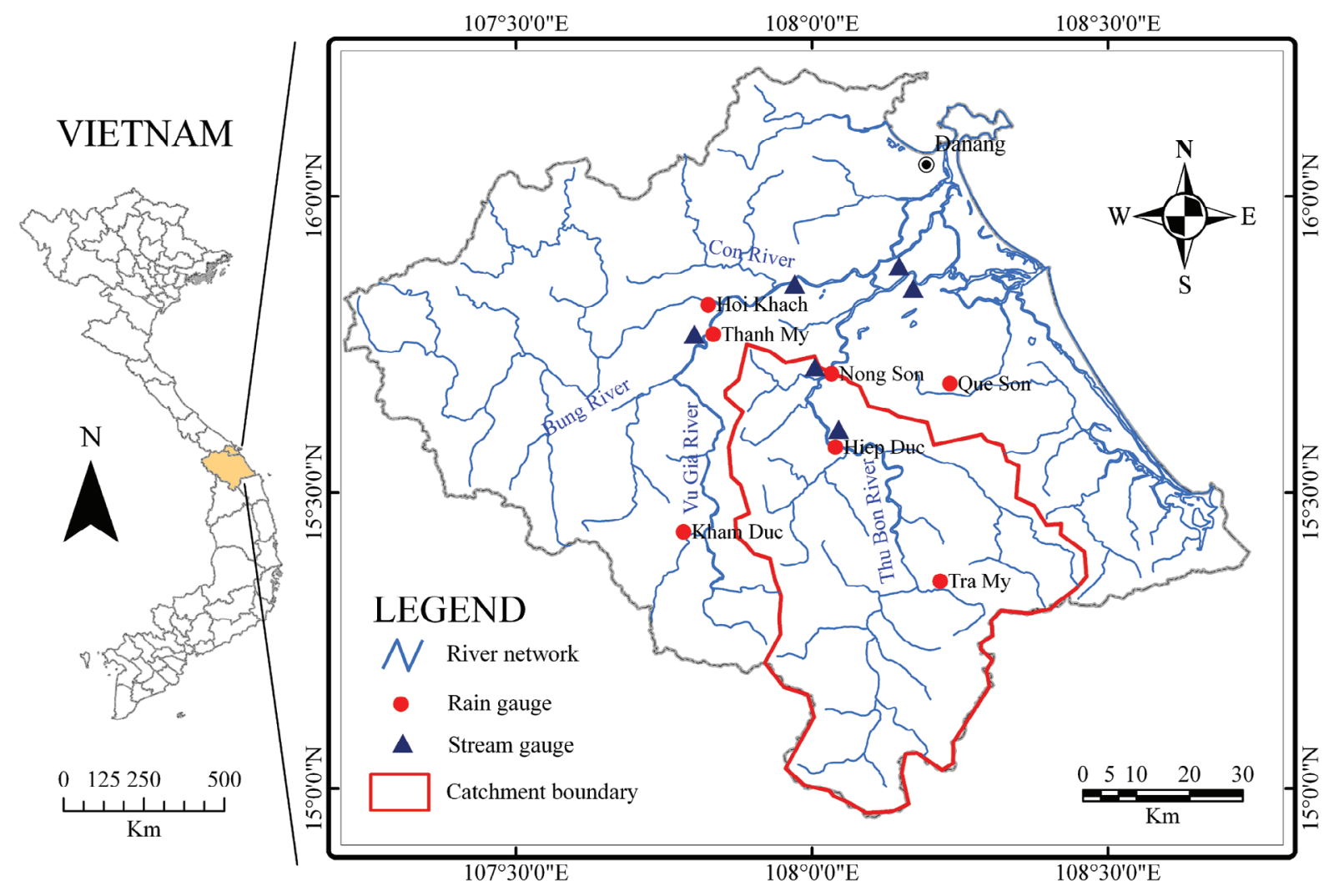

Fig. 1. Map of the Vu Gia-Thu Bon River system in Central Vietnam and locations of hydro-meteorological stations.

fidence for most scenarios. With respect to future climate projections, the CGCM simulates a number of scenarios that are in line with different estimates of greenhouse gas and $\mathrm{CO}_{2}$ concentration, for instance, scenarios $\mathrm{A} 1 \mathrm{~B}, \mathrm{~A} 2$, B1, among others. However, within the scope of the present study the climate change impacts will be analyzed using the projection of future climate under scenario $\mathrm{A} 1 \mathrm{~B}$, the very likely scenario that keeps a balance consumption among all energy sources. Model output gives monthly averaged estimates of temperature, precipitation, humidity, pressure, wind velocity, and so on.

The study takes a convention that precipitation obtained from rain gauges is referenced rainfall (true rainfall). Seven rain gauges (Fig. 1) which measure daily rainfall either in or nearby the catchment boundary are selected for the analysis. A stream gauge at the outlet of the catchment is used for a runoff simulation and variation assessment. These hydrometeorological stations have provided a continuous record since 1981 .

\subsection{Statistical Downscaling Model}

Given the limitations of physical representation of the real world and computing capability, GCMs are dealing with relatively simple parameterization schemes and coarse spatial resolutions, grid cell distances on the order of hun- dreds of kilometers. These spatial resolutions are too coarse for hydrological simulations or local-scale climate research which usually require resolutions of about hundreds of meters for small-size catchments to a couple of kilometers for large-size basins. In addition, the land surface is averaged within very coarse grid cells; thus, small-scale effects of topography may not be resolved in these GCMs. As a result, direct output from GCMs is usually subject to significant discrepancies such as precipitation that is well known as the most unpredictable variable.

The statistical downscaling is based fundamentally on the formulation of either linear or nonlinear relationships between large-scale atmospheric variables simulated by GCMs (usually referred as predictor variables) and local or single site scale variables (or so called predictand variables). These statistical relationships are then used to improve the direct model output of the GCMs. With respect to the formulation of empirical relationships between predictands and predictors, downscaling schemes are dependent on the selection of transfer function, predictor variables, and statistical fitting procedures (Wilby et al. 2002). In the context of this research, one of the most simple and popular artificial neural network (ANN) architectures which are commonly used in statistical downscaling, the feed-forward multilayer perceptron using error back-propagation weight update rule (Fig. 2), hereafter simply referred as ANN, is employed for 


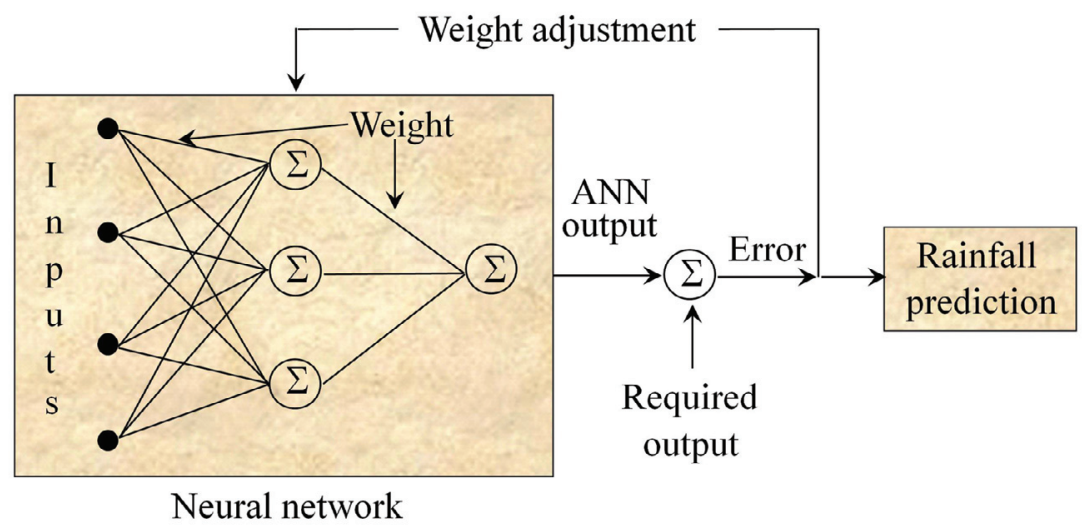

Fig. 2. Architecture of a feed-forward ANN with back-propagation algorithm.

precipitation estimates. In terms of learning skill, ANN is generally observed to perform a better learning ability than the other regression-based downscaling techniques (Schoof and Pryor 2001). Details of the ANN structure and learning algorithm were described in literature (Nam et al. 2011a).

The most crucial part of any statistical downscaling model is perhaps the selection of predictor variables. GCMs can give a large number of model output variables at different pressure layers, so that there are always more potential predictors available than those really need for a statistical prediction procedure. The selection of most significant predictor variables for the formulation of empirical relationships, therefore, is most important. Inclusion of less relevant predictor variables in prediction equations may lead to the case of overfitting. The data which the excellent fit is achieved on the dependent data, but the fitted relationship is unable to perform with independent data exclusion from the development of the prediction equation (Wilks 2006). The optimized process of predictor variables selection should consider first those predictor variables that are meteorologically reasonable, given the physical processes associated with the particular climate pattern to be simulated, for instance, the prevailing synoptic climate conditions over targeted regions. Second, in case absence of meteorological and physical interpretations, purely empirical selection of predictor variables should be performed (Kuligowski and Barros 1998). In line with the scope of the present research which attempts to downscale the large-scale monthly averaged precipitation derived from CGCM output so that meteorological interpretations are not properly defined, the later empirical selection of predictor variables is employed. A stepwise multiple linear regression method is then used to select the most statistically significant predictor variables.

\subsection{Hydrological Model}

With respect to a rainfall-runoff analysis, the tank model that was first introduced by Sugawara (1967) has exhibited a simple lumped model, but it shows a great ability in runoff simulation. As a conceptual model the tank model, however, has many parameters that require calibration. The super-tank model used in this study for rainfall runoff analysis apparently tends to overcome this issue. The model is also based on the original tank, attributed with some physically based features (Kardhana et al. 2007; Nam et al. 2011b). The super-tank model, thus, has nearly calibration-free parameters, because the model parameters are internally calibrated using geo-topographical and landsurface information. Furthermore, given a semi-distributed hydrologic model the super-tank model is assumed to outperform lumped hydrologic models in terms of spatial variation consideration. As a result, the super-tank model has successfully demonstrated its robustness and universality in rainfall runoff modeling, across a wide range of spatial and temporal scales, especially the scarce observation catchments.

With regard to the vertical structure of the super-tank model, the sub-basin storage consists of linear cascade tanks that are illustrated in Fig. 3. The top 2 tanks represent the precipitation input and canopy interception respectively. Meanwhile the 3 sub-surface tanks represent the interflows; the bottom tank, referred as the groundwater layer, represents the baseflow. In the context of this study given the limitation of hydro-geological information of the groundwater layer, a lump tank that represents the contribution of groundwater of the whole basin is used. Therefore, calibration for lump parameters, the gradient and initial storage of the groundwater tank applied for all grid cells is required. The generation of flow in channel networks is considered as a result of lumped flow to the channel nodes and flood routing in the channels. Further model description and governing equations were presented in the literature (Kardhana et al. 2007).

The evaluation of runoff model performance is based on the Nash Sutcliffe Index (NSI), or so-called coefficient of model efficiency, which is expressed in Eq. (1) below. 


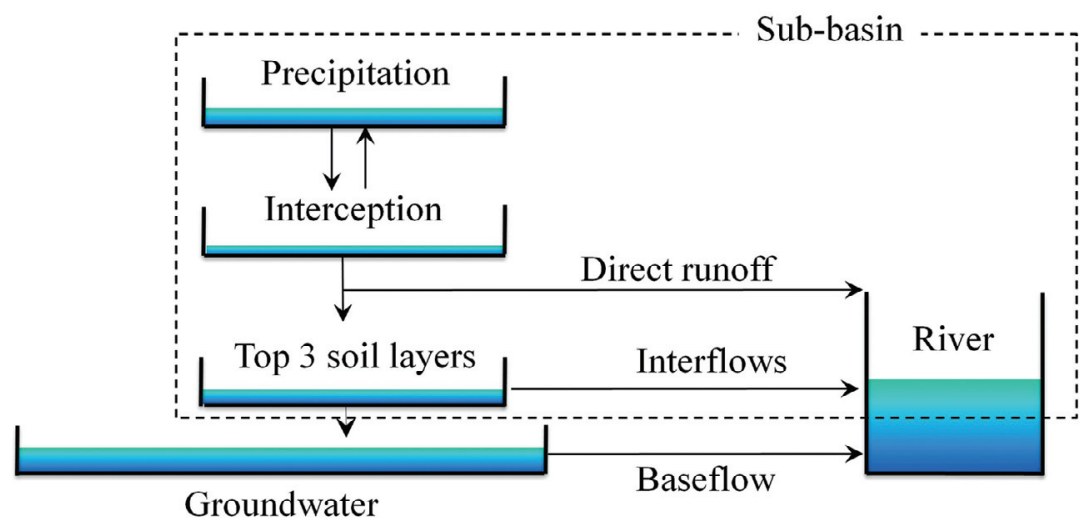

Fig. 3. Schematic of the super-tank model.

$N S I=1-\frac{\sum\left(Q_{o b s}-Q_{c a l}\right)^{2}}{\sum\left(Q_{o b s}-\bar{Q}_{o b s}\right)^{2}}$

where, $Q_{o b s}=$ observed monthly streamflow; $\bar{Q}_{o b s}=$ observed monthly mean streamflow; $Q_{\text {cal }}=$ calculated monthly streamflow.

\section{RESULTS AND DISCUSSION}

\subsection{Downscaled Precipitation}

Surface climate analysis based on GCMs output is typically conducted for individual points, sub-grid scale or area-average bases. The GCMs output is provided as a gridpoint-value averaged over a grid cell. Using area-average downscaling approach apparently tends to reduce scale effects, in particular when the catchment size is large. Predictor variables from neighbor grid points are preliminarily interpolated and then averaged over the study basin using inverse distance weighting method. The same procedure is conducted for the ground rainfall observation points for areal estimate of actual precipitation.

The downscaling process of large-scale precipitation in this study is divided into a training phase and validation phase, using CGCM output and historical precipitation for periods 1981 - 2000 and 2001 - 2010 respectively. Downscaled precipitation is performed on monthly averaged basis which is in line with temporal resolution of the CGCM output.

Large-scale atmospheric variables provided by the CGCM output for public uses are presented in Table 1. These variables are considered to be candidate predictors. Based on predictor variable screening process using the stepwise multiple linear regression method, the optimal predictor variables for model training are determined and presented in Table 2 . These selected predictor variables are used to formulate the statistical downscaling model. The ANN architecture, therefore, comprises an input layer of 5 nodes, a single hidden layer of 10 nodes, and the downscaled precipitation in the output layer. A simple source code written by Brierley (1998), the Tiberius, is employed for model training.

The statistical downscaling model is first trained using historical data in the period 1981 - 2000. Monthly time series of downscaled results are averaged over this period. Figure 4 illustrates the comparison of monthly mean precipitation during 1981 - 2000 derived from CGCM output, statistical downscaling model using ANN, and actual observation. It is obvious that the large-scale precipitation estimated by the CGCM depicts very large discrepancies compared to those measured by rain gauges, particularly in wet months lasting from October to December. On the other hand, the statistical downscaling model using ANN has demonstrated significant skill in estimating precipitation. It shows a very good agreement with the actual rainfall observed in the field, except slight underestimates are found at the end of the wet period. Area-averaged correlation coefficient of 0.98 is attained.

The formulated empirical relationship between the actual rainfall observed by rain gauges and large-scale variables derived from CGCM output is then applied for the estimate of downscaled precipitation in the validation phase during 2001 - 2010. The comparison is also made similarly for the monthly mean precipitation. Validation results are illustrated in Fig. 5. It is found that the statistical downscaling model has successfully proved its ability to derive local-scale precipitation from large-scale predictor variables simulated by CGCM although minor discrepancies are also observed. This leads to a minor underestimation of precipitation given by the proposed downscaling model.

In order to project future precipitation over the study area, the validated statistical downscaling model is then utilized to perform the prediction of precipitation in future scenarios under the scenario A1B for medium-term (2040 - 2069) and long-term (2070 - 2099). Projected results are averaged over these periods, subsequently compared the 
baseline precipitation (1981 - 2000). Figure 6 presents future changes in precipitation relative to the baseline period. Results show that there will be not much variability of precipitation in the future, except significant variations found in September (negative) and January (positive). It is presumably understood as the potential of seasonal variation that shifts wet months, currently, from September-December to October-January in the future. In other words, the wet season tends to be delayed in onset and late in withdrawal (Kitoh and Uchiyama 2006).

\subsection{Runoff Simulation}

One of the greatest advantages of the super-tank model is its nearly calibration-free parameters. Theoretically, the 4 parameters of the model are required calibration. However, these parameters have been optimized through the physical interpretation or similarity. The interception storage capacity $(S)$ is selected at the value of $0.025 \mathrm{~m}$ (Kardhana et al. 2007). The infiltration rate has been controlled by the top soil saturated hydraulic conductivity. $c$ is a dimensionless modification coefficient on the saturated hydraulic conductivity that represents the assumed deviation between estimation and actual interflow from the Darcy Law given the nature of soil structure. The $c$ coefficient tends to be the universal number, found at the optimal value of 10 (Kato and Mano 2003; Kardhana et al. 2007; Nam et al. 2012). $a$ coefficient is used to determine the distribution of roughness coefficient in river. The $a$ coefficient is determined with the value of 0.15 for this study basin.

Calibration for lump parameters, the gradient and initial storage of the groundwater tank, applied for all grid cells is conducted here simply based on trial and error approaches using historical rainfall and flow data of during the period
1981 - 1990. The best values for the groundwater tank gradient and initial storage are found of 5.0E-2 and one fourth of the tank depth (approximate $10 \mathrm{~m}$ ) respectively. Model validation is performed for the period 1991 - 2000. Results showed that the simulated hydrograph agreed very well with the observed hydrograph (Fig. 7); most high flow periods are captured by the runoff model. Coefficient of model efficiency $(N S I=0.71)$ is attained for the overall model performance.

Table 1. Candidate predictor variables for model calibration.

\begin{tabular}{clc}
\hline No. & \multicolumn{1}{c}{ Variables } & Unit \\
\hline 1 & Near surface specific humidity & 1 \\
2 & Precipitation flux & $\mathrm{mm} \mathrm{month}^{-1}$ \\
3 & Air pressure at sea level & $\mathrm{Pa}$ \\
4 & Surface down welling short-wave flux in air & $\mathrm{W} \mathrm{m}$ \\
5 & Air temperature & ${ }^{\circ} \mathrm{C}$ \\
6 & Eastward wind speed & $\mathrm{m} \mathrm{s}^{-1}$ \\
7 & Northward wind speed & $\mathrm{m} \mathrm{s}^{-1}$ \\
8 & Wind speed & $\mathrm{m} \mathrm{s}^{-1}$ \\
\hline
\end{tabular}

Table 2. Selected predictor variables for model training.

\begin{tabular}{clc}
\hline No. & \multicolumn{1}{c}{ Variables } & Unit \\
\hline 1 & Near surface specific humidity & 1 \\
2 & Precipitation flux & $\mathrm{mm} \mathrm{month}^{-1}$ \\
3 & Air pressure at sea level & $\mathrm{Pa}$ \\
4 & Air temperature & ${ }^{\circ} \mathrm{C}$ \\
5 & Wind speed & $\mathrm{m} \mathrm{s}^{-1}$ \\
\hline
\end{tabular}

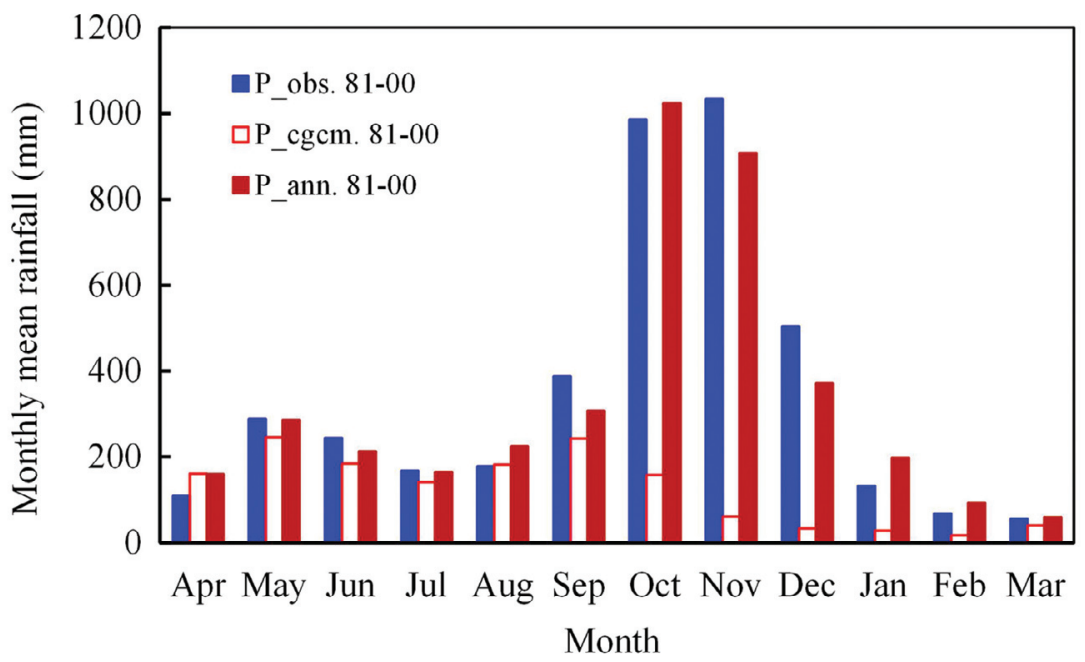

Fig. 4. Hyetograph of observed rainfall (P_obs) and those directly derived CGCM output (P_cgcm) and statistical downscaling model (P_ann) for the training phase, $1981-2000$. 


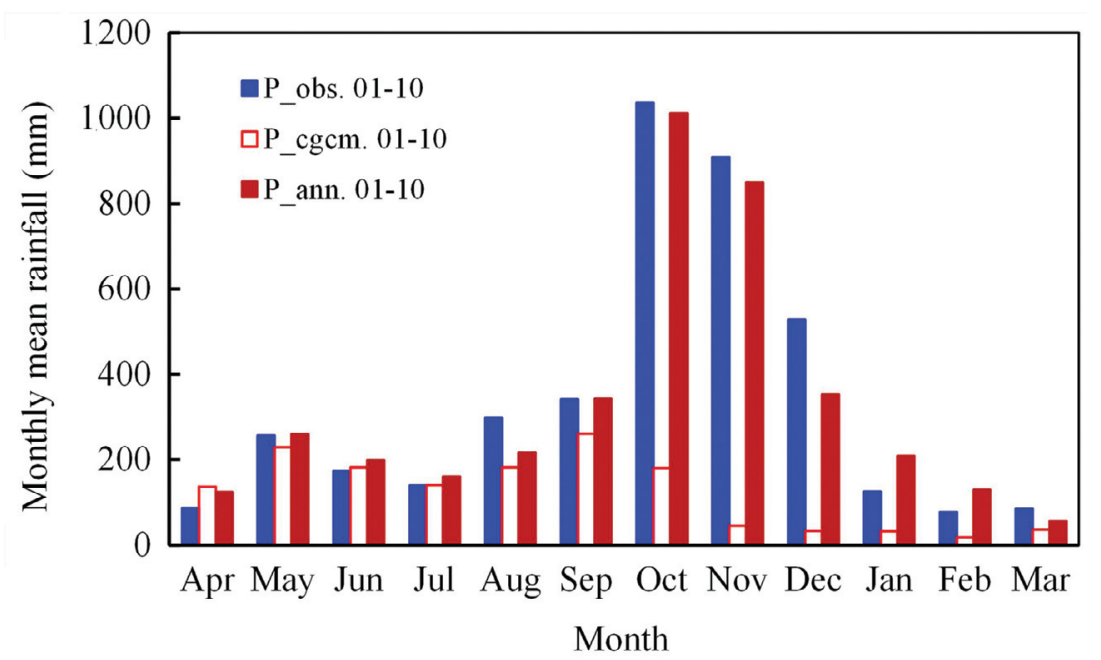

Fig. 5. Hyetograph of observed rainfall (P_obs) and those directly derived CGCM output (P_cgcm) and statistical downscaling model (P_ann) for the validation phase, $2001-2010$.

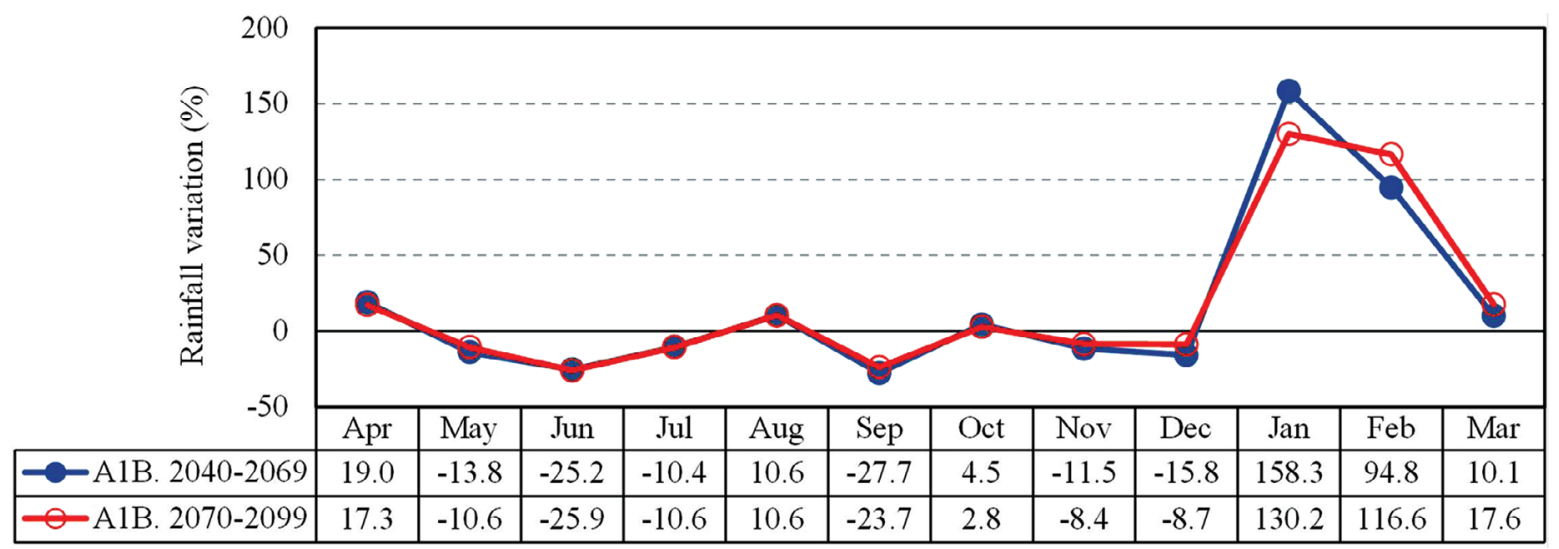

Fig. 6. Medium-term and long-term projections of changes in monthly mean precipitation relative to the baseline, 1981 - 2000.

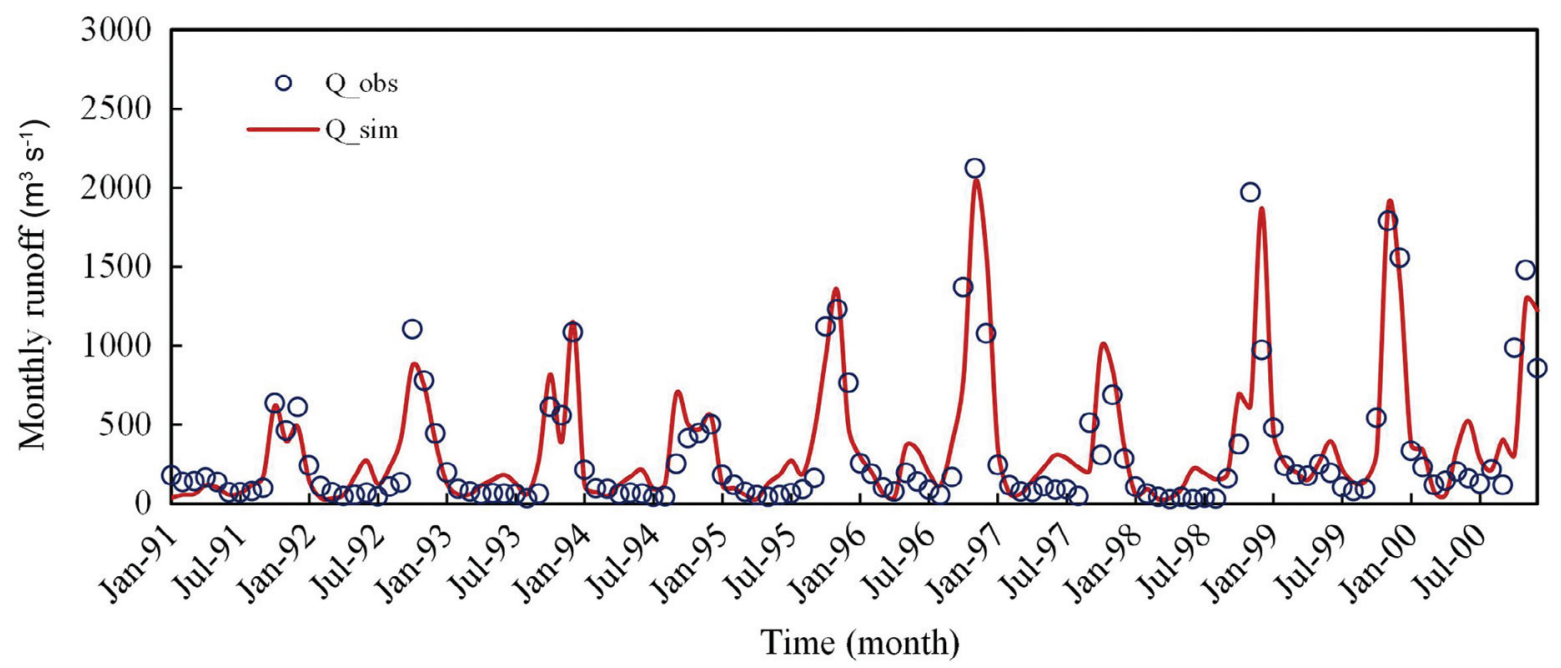

Fig. 7. Time-series of observed and simulated monthly discharge for the model validation, 1991 - 2000. 
Another validation procedure is conducted for the downscaled precipitation which is estimated by the statistical downscaling model (using ANN). Monthly mean precipitation downscaled by ANN (P_ann) in the validation period 2001-2010 is used as input for the super-tank model for runoff simulation. It can be observed in Fig. 8 that the simulated hydrograph exhibits a very good agreement with the actual hydrograph; it is comparable to those reproduced using rainfall information from rain gauges. Overall model performance is evaluated through the coefficient of model efficiency $(N S I=0.9)$. As a result, validations of statistical downscaling model and runoff model for the estimate and simulation of monthly mean precipitation and runoff, respectively, demonstrate a high level of confidence for the application of these calibrated models in future climate and runoff analysis.

\subsection{Projection of Runoff Variation}

In order to assess the potential runoff responses to climate change impact, the medium-term and long-term projections of precipitation based on downscaling model will be used to simulate river flow. Simulated results are then compared to those in the baseline at the end of the $20^{\text {th }}$ century.

Though changes in precipitation are regionally dependent, increase in surface temperature has been observed for the entire globe (IPCC 2007). Projection of significant increase in future surface temperature is likely to enhance evapotranspiration processes so that higher evapotranspiration rate is expected. It will directly influence runoff generation processes, so that the inclusion of variation in evapotranspiration rate is essential for runoff assessment. Projection of potential evapotranspiration (PET) rate in this study is simply based on climatic average monthly temperature. Malmström (1969) introduced a method for the estimate of monthly climatic PET as expressed in Eq. (2) below.

PET $=40.9 e_{s}^{*}\left(T_{s}\right)$

where $e_{s}^{*}$ is the saturation vapor pressure at the surface temperature $\left(T_{s}\right)$ and determined in Eq. (3).

$e_{s}^{*}=0.611 \exp \left(\frac{17.3 T_{s}}{T_{s}+237.3}\right)$

Here, the the saturation vapor pressure and surface temperature are in $\mathrm{kPa}$ and ${ }^{\circ} \mathrm{C}$ respectively.

In the context of this study, projection of surface temperature is directly derived from the CGCM output. It is simply explained as the CGCM actually exhibits very good estimates of surface temperature. Correlation coefficient between simulated and observed temperature is about 0.9 for the baseline period. However, the CGCM slightly overestimates and underestimates the temperature in cold and hot months respectively so that the same order of errors in PET estimates is expected. As a result of rising surface temperature, of about $1.2^{\circ} \mathrm{C}$ and $1.8^{\circ} \mathrm{C}$ by the middle and the end of the century respectively relative to the baseline period 1981 - 2000, results show that the averaged PET in 2040 2069 and 2070 - 2099 will increase about $9 \%$ and $13 \%$ of that order relative to the baseline period (Fig. 9). It seems to underestimate for July and August.

Subsequently, the simulations of runoff corresponding to these scenarios are conducted using the super-tank model. Simulated hydrographs are illusttraed in Fig. 10. It is compared to the discharge observed in the baseline period. In general, the runoff generation depicts a similar behavior with those obseved in the baseline period except a slower declination towards the recession limb in January and Feb-

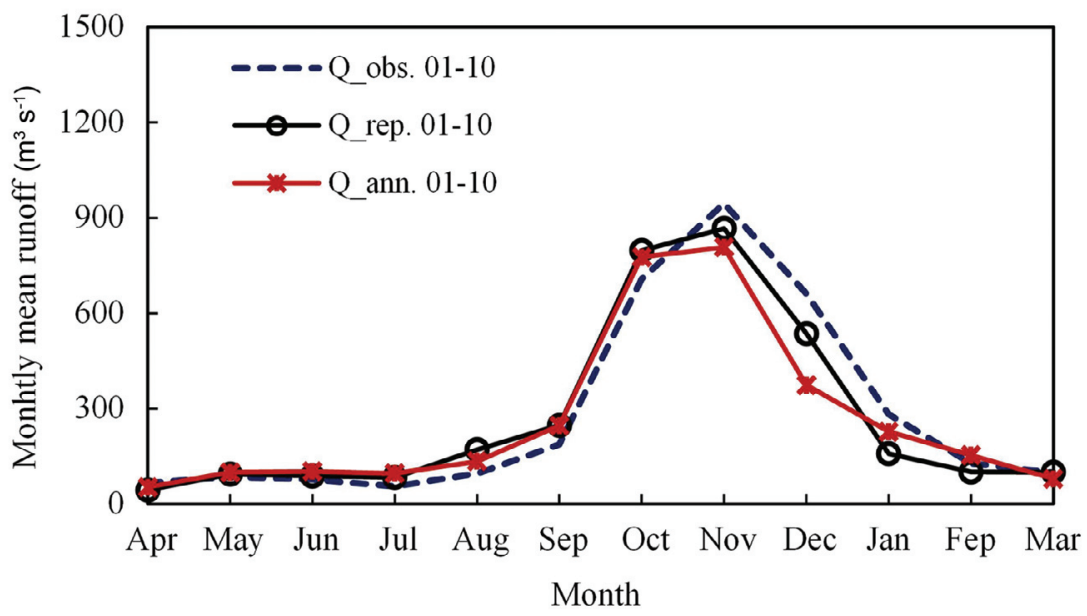

Fig. 8. Hydrographs of observed and simulated monthly mean discharge for the model validation, $2001-2010$. 


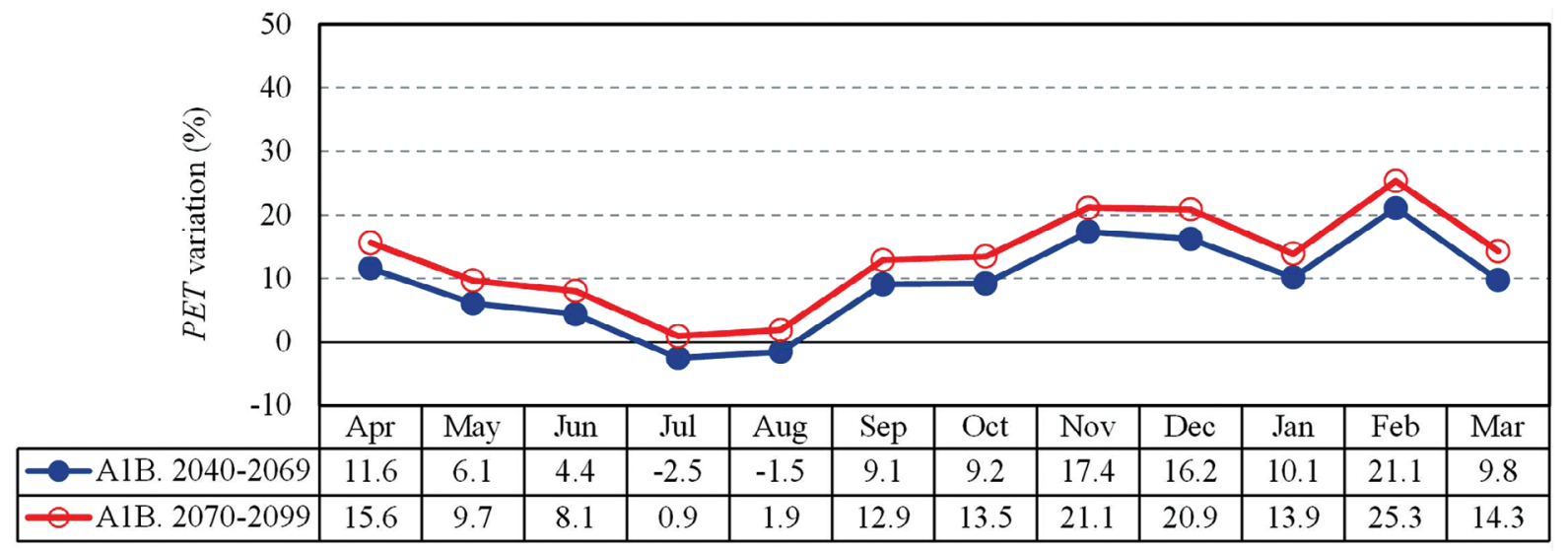

Fig. 9. Medium-term and long-term projections of changes in monthly potential evapotranspiration (PET) relative to the baseline, 1981 - 2000.

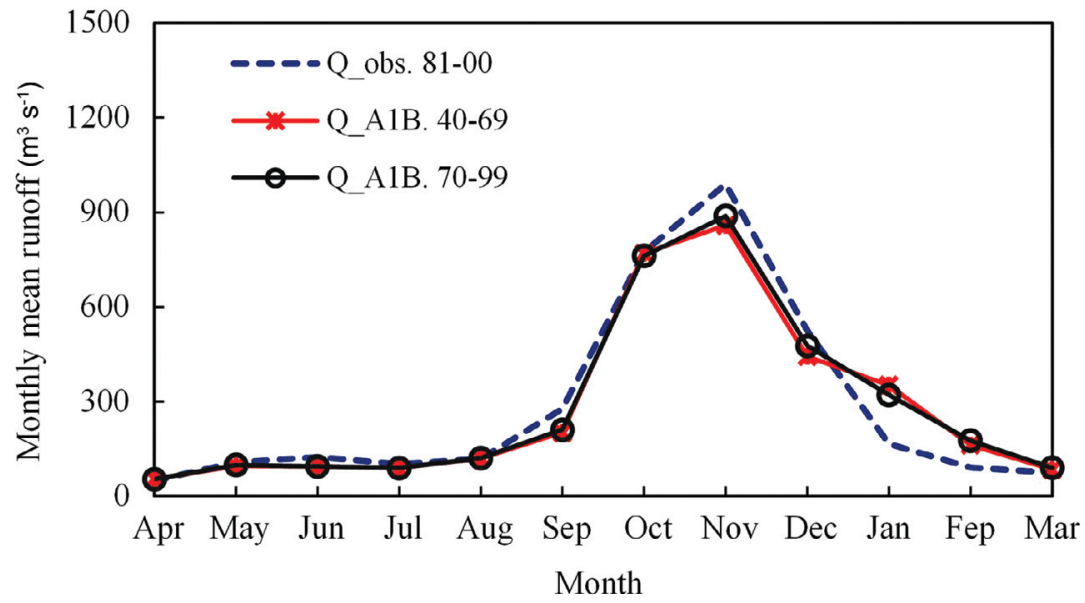

Fig. 10. Hydrographs of observed and projected monthly mean discharge for the middle and the end of this century.

ruary for both cases (medium-term and long-term). It could be explained due to the late withdrawal of the wet period.

Quantitative evaluation of monthly runoff variation relative to the baseline period is presented in Fig. 11. There is a tendency that climate change will cause impacts on the runoff regimes towards a decline in a dry period and a longer duration of high streamflow. As a result of the delayed onset of the wet season, a considerable runoff reduction is observed in September of about $25 \%$. While an approximate a double increase of runoff is found in January and February given by the late withdrawal. It is also found that future runoff will not vary much between these two scenarios. With respect to catchment water balance, both medium-term and long-term projections show almost a similarity in annual runoff relative to the baseline period. This is perhaps due to the increasing PET rate over time while a slight increment of precipitation is projected.

It is obvious that variation in runoff regimes will propbably lead to potential impacts on an ecosystem, envi- ronment, and activities not only within the catchment scale, but also downstream. Reduction of water availability in a dry season accompanied by rising surface temperature tends to raise pressure on water resources. In addition, the low river flow in a dry season will enhance further inland salinity instrusion so that cultivable area becomes lessened. Agricultural production, therfore, is projected to decrease. An increasing water shortage might also increase level of water conflicts. On the other hand, land use change together with a rapid urbanisation process will increase risk of flood disaster which its intensification and level of severity are more frequently expected.

\section{CONCLUSIONS AND REMARKS}

It is very likely that climate change will be a major concern for the mankind, ecosystem, and environment. Developing a strategy for adaptation is one of a number of efficient responses to climate change impacts. This research 


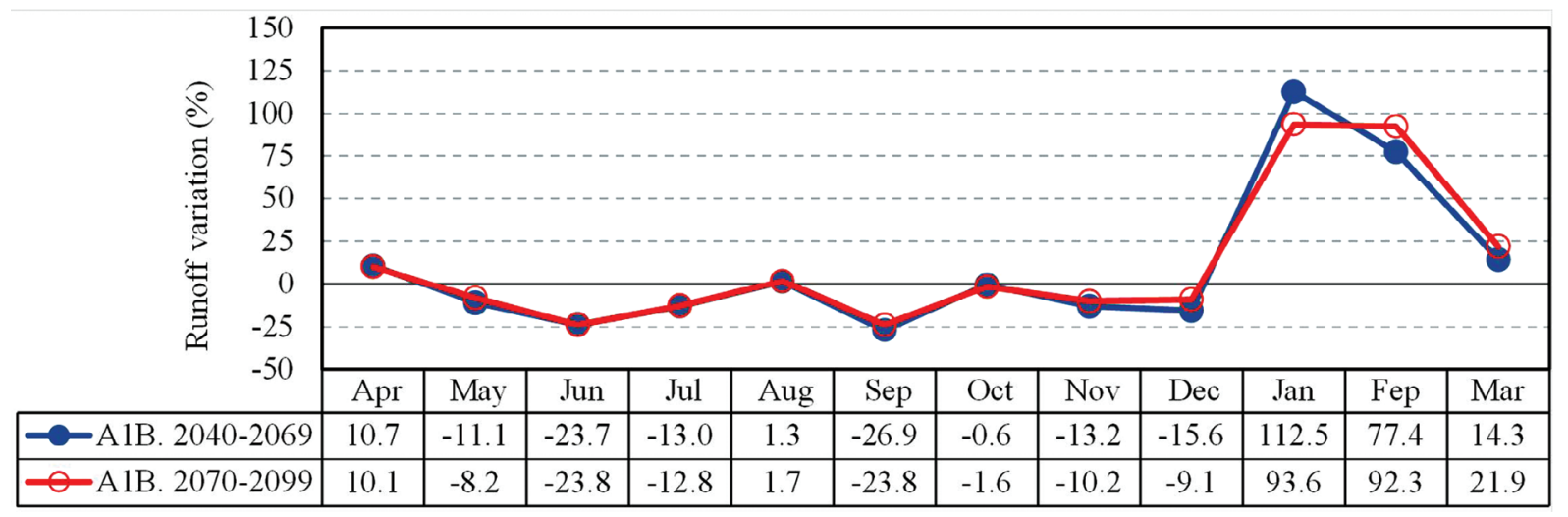

Fig. 11. Medium-term and long-term projections of changes in monthly streamflow relative to the baseline, 1981 - 2000.

attempts to explore the hydrological responses to the impacts through the assessment of runoff regimes in the future based on downscaled precipitation from large-scale variables simulated by the CGCM and the runoff model. Medium-term and long-term impacts have been examined at a river basin scale in Central Vietnam. Preliminary findings are summarized as follow:

(i) Coupling between a statistical downscaling model and distributed runoff model has demonstrated a useful technology in climate change impact assessment on water resources. The simplicity of model structure allows these models to be easily implemented across a wide range of temporal and spatial scales. Due to less computational demands and calibration requirements, the coupled model has become a robust tool in runoff assessment, especially in scattered/ungauged catchments.

(ii) In medium-term and long-term projections, the averaged annual runoff is found not to be really distinctive relative to the baseline period 1981 - 2000 though precipitation is slightly increased. This is perhaps due to the substantial increase of evapotranspiration rate caused by temperature rising. Regarding seasonal variation, the runoff is projected decreasing in the dry season and increasing in the rainy season.

(iii) As a result of delay in onset and late withdrawal of the wet season, the high flow period tends to shift from September - December at present to October - January in the future.

In the next steps of the current study, it is planned to concentrate on extreme event projection using the super high resolution global climate model (20 km grid cell distance) which is also experimented by MRI \& JMA. It is hoped to provide higher level of confidences for each projection scenario. So that the outcome would possibly be a vital tool for planning and management at river basin scales in response to climate change impacts.

Acknowledgements This study is under the financial sup- port of the Japan Society for the Promotion of Science (JSPS), and JST/JICA, SATREPS (Science and Technology Research Partnership for Sustainable Development).

\section{REFERENCES}

Brierley, P., 1998: Some practical application of neural networks in the electricity industry. Ph.D. Dissertation, Cranfield University, Cranfield, UK.

Gellens, D. and E. Roulin, 1998: Streamflow response of Belgian catchments to IPCC climate change scenarios. J.Hydrol., 210, 242-258, doi: 10.1016/S0022-1694(98) 00192-9. [Link]

IPCC (Intergovernmental Panel on Climate Change), 2007: An Assessment of the Intergovernmental Panel on Climate Change. Synthesis Report.

Kardhana, H., H. Tatesawa, and A. Mano, 2007: Flood forecast based on numerical weather prediction and distributed runoff model. In: Brebbia, C. A. and K. L. Katsifarakis (Eds.), River Basin Management IV, WIT Press, 201-211, doi: 10.2495/RM070201. [Link]

Kato, H. and A. Mano, 2003: Flood runoff model on one kilometer mesh for the Upper Chang Jiang River. Proceeding of GIS \& RS in Hydrology, Water Resources, and Environment, 1, 1-8.

Kitoh, A. and T. Uchiyama, 2006: Changes in onset and withdrawal of the East Asian summer rainy season by multi-model global warming experiments. J. Meteorol. Soc. Jpn., 84, 247-258, doi: 10.2151/jmsj.84.247. [Link]

Kuligowski, R. J. and A. P. Barros, 1998: Localized precipitation forecasts from a numerical weather prediction model using artificial neural networks. Weather Forecast., 13, 1194-1204, doi: 10.1175/1520-0434(1998)0 13<1194:LPFFAN>2.0.CO;2. [Link]

Malmström, V. H., 1969: A new approach to the classification of climate. J. Geogr., 68, 351-357, doi: 10.1080/ 00221346908981131. [Link] 
Nam, D. H., K. Udo, and A. Mano, 2011a: Downscaling global weather forecast outputs using ANN for flood prediction. J. Appl. Math., 246286, 1-14, doi: 10.1155/2011/246286. [Link]

Nam, D. H., K. Udo, and A. Mano, 2011b: Flood forecasting and early warning for river basins in Central Vietnam. Ann. J. Hydraul. Eng. (JSCE), 67, 7-12, doi: 10.2208/ jscejhe.67.I_7. [Link]

Nam, D. H., K. Udo, and A. Mano, 2012: Inflow forecast using downscaled rainfall from global NWP for realtime flood control. Ann. J. Hydraul. Eng. (JSCE), 68, 181-186.

Schoof, J. T. and S. C. Pryor, 2001: Downscaling temperature and precipitation: A comparison of regressionbased methods and artificial neural networks. Int. J. Climatol., 21, 773-790, doi: 10.1002/joc.655. [Link]

Sugawara, M., 1967: The flood forecasting by a series stor- age type model. International Symposium Floods and Their Computation, International Association of $\mathrm{Hy}$ drologic Sciences, 1-6.

Wilks, D. S., 2006: Statistical methods in the atmospheric sciences. Academic Press, second edition, 210-211.

Wilby, R. L. and T. M. L. Wigley, 1997: Downscaling general circulation model output: A review of methods and limitations. Prog. Phys. Geogr., 21, 530-548, doi: 10.1177/030913339702100403. [Link]

Wilby, R.L., C. W. Dawson, and E.M. Barrow, 2002: SDSM - A decision support tool for the assessment of regional climate change impacts. Environ. Modell. Softw., 17, 145-157, doi: 10.1016/S1364-8152(01)00060-3. [Link]

$\mathrm{Xu}, \mathrm{C} .$, 1999: From GCMs to river flow: A review of downscaling methods and hydrologic modelling approaches. Prog. Phys. Geogr., 23, 229-249, doi: 10.11 77/030913339902300204. [Link] 